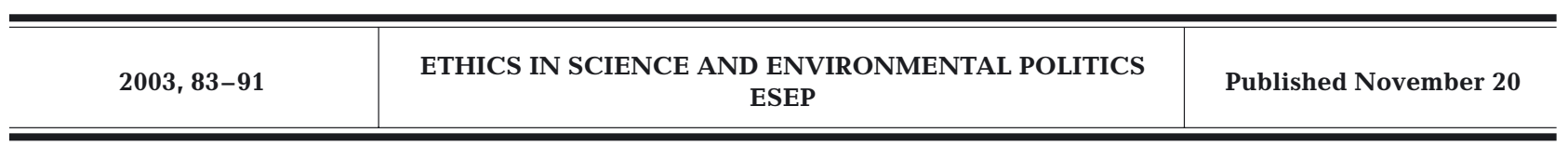

\title{
PAPER
}

\section{Numeracy and sustainability}

\author{
John Cairns, Jr.* \\ Department of Biology, Virginia Polytechnic Institute and State University, Blacksburg, Virginia 24061, USA
}

\begin{abstract}
Sustainable use of the planet is based on the assumption that humankind can maintain conditions suitable for inhabiting the planet indefinitely. No robust evidence supports this assumption nor rejects it, and adequate evidence on this issue may not be available for centuries. Numeracy is the ability to use or understand numerical techniques of mathematics. Even if adequate numerical data were available, the important decisions humankind makes regarding sustainable use of the planet should not be guided by numerical information alone, such as economic numbers, but by ecoand sustainability ethics, which provide a values framework that indicates how the numbers should be used and interpreted.
\end{abstract}

KEY WORDS: Sustainability $\cdot$ Numeracy $\cdot$ Eco-ethics $\cdot$ Sustainability ethics $\cdot$ Sustainable development

Resale or republication not permitted without written consent of the publisher

The trouble with our times is that the future is not what it used to be. Paul Valery

\section{INTRODUCTION}

Sustainable use of the planet is based on the assumption that humankind has the right to alter the planet so that human life can inhabit Earth indefinitely. In doing so, environmental conditions of the planet may be shifted so that they are optimal for one species, but not necessarily for all species or even a majority of species now alive. Clearly, humankind does not value all life equally. Sustainability is based on the assumption that acceptable environmental conditions can be maintained. The assumption has not been validated, nor is it likely to be for centuries, if ever. Numeracy is the ability to use or understand numerical techniques of mathematics (a useful introduction is available in Bartlett 1994). However, the important decisions humankind makes should not be based on numbers, even economic numbers, but rather on eco- and sustainability ethics, which provide a values framework that indicates how the numbers should be used and interpreted. The emphasis on severely limited numbers is a major weakness of the United Nations Commission on Environment and Development (1987) report, which focused on development (commonly regarded as synonymous with growth). Development is just one metric valued by one species. Sustainability involves a variety of metrics for a complex, multivariate living system called the interdependent web of life.

Sustainability is the study of patterns involving all forms of life and the conditions necessary for them to flourish as a community. One can place an infinite value on human life and on other life forms as well. One can place an infinite value on one's own life but be willing to sacrifice it to protect one's offspring. This example illustrates that there can be more than one value for infinity. Sustainability involves a similar situation - humankind must place infinite value on personal life, on the lives of its future generations, and on those of other life forms. Balancing these seemingly incompatible values will never be fully achieved since 
life consists of dynamic and stochastic events that will frequently alter the factors affecting this precarious balance. Sustainability policies may be developed for individual components (e.g. agriculture, transportation, energy, communities, fisheries), but achieving sustainability will not be possible unless the policies are integrated into a master policy and plan that does not adversely affect other components. Numeracy will be helpful in establishing component balancing.

\section{USING AVAILABLE NUMERICAL DATA}

Numbers influencing sustainability are simple and straightforward but are either ignored or misunderstood by policy makers and the general public. As a consequence, unethical and unsustainable practices and behaviors are termed 'practical,' 'essential,' 'good for the economy,' 'compassionate,' and even 'religious.' Arguably, the greatest threat to sustainability is the misinformation on the dangers of human population growth (Bartlett 1998). As Bartlett (1998) notes, the more optimistic the prediction the greater the probability that the prediction is based on faulty arithmetic or no arithmetic at all. The human population cannot continue to grow exponentially and indefinitely on a finite planet. The debate on population growth began over 200 years ago with Malthus' (1798) insightful publication. At the root of this controversy is the denial of limits. Hardin (1993) provides a superb illustration (starting with a single lily pad of a specific size in a pond of a specific size and a specific rate of increase) of how rapidly a limit can be reached when exponential growth occurs even when no problem is apparent at present. This illustration could be applied to a population of any species on the planet-including humans. When will the pond be covered with lily pads? Assuming a daily doubling rate, the capacity will be reached on the 30th day. However, the pond would only be half covered on the 29th day. Seeking new resources will not avert reaching the limits since doubling the size of the pond will only postpone saturation (i.e. reaching the capacity) for one day; quadrupling the size of the pond would only add two days. In short, all appears well until the final doubling. After the 30th day, the lily pads produced would suffer seriously due to lack of space. Clearly, other life forms in the pond would also suffer at this stage. Emotional reasons that could lead to refusal to accept this reality for populations of humans may ultimately cost billions of lives.

This important issue of exponential growth can be examined by anyone with a pocket calculator or a pencil and a sheet of paper. For example, starting with one of anything, ten doublings will produce the astonishing number of 512. An estimate of doubling time can be calculated by dividing the growth rate into 70. A $2 \%$ population growth rate per year (considered modest these days) results in a doubling time of 35 years. An island with a carrying capacity of 256 people would be in deep trouble with a single doubling. By ignoring simple numbers, humankind places itself at great risk.

\section{ECOLOGICAL FOOTPRINTS}

The average ecological footprint of a North American (essentially the amount of land that would be necessary to support a defined economy sustainably at its current material standard of living) is 4 to 5 hectares (Wackernagel \& Rees 1996). At a $2 \%$ annual human population growth rate, 8 to 10 hectares would be need in 35 years to maintain the footprint size. On a finite planet, unrestrained exponential growth is idiocy!

The Netherlands (National Institute for Public Health and Environmental Protection 1992) has a smaller ecological footprint (3.32 hectares per capita) than the US and Canada, but a standard of living above the average for the entire planet. However, even a small population growth rate can quickly reduce the available hectares per capita. At a $1 \%$ annual human population growth rate, the doubling time would be approximately 70 years. The ecological footprint size would be reduced to 1.66 hectares per capita in the Netherlands (and consequently a much lower standard of living) if the resource base remained constant. This situation would result in halving the per capita resources if the resource base were not doubled. Obviously, humankind cannot send the entire population 'surplus' to other planets during the 70-year doubling time.

In stark contrast, the ecological footprint size in India is 0.38 hectares per capita (Wackernagel \& Rees 1996). Worse yet, the estimated footprint size of the average person in India in the bottom $50 \%$ of income earners is roughly 0.2 hectares per capita (Wackernagel \& Rees 1996). Thus, the present condition is already unsatisfactory. If the global carrying capacity for humans is reached or exceeded on a finite planet, then consumption by the rich must be markedly reduced to shift resources to the poor or the latter will suffer or die. This problem is one of eco-ethics, although numerical data provide useful information on how much needs to be done once it is decided what to do. Living at higher densities reduces the ecological impact because it does not require as much land for urban sprawl and, properly managed, has a lower energy consumption. Wackernagel \& Rees (1996) provide an excellent illustration of comparative ecological footprint size for traveling $5 \mathrm{~km}$ each work day-bicycles, approximately 122 square meters/capacity; buses approximately 
301 square meters/capacity, and automobiles; 1,442 square meters/capacity. In addition, food is also a major factor that determines ecological footprint size.

Brown (2000) estimates 1.1 billion hungry people on the planet. Since poverty and hunger are closely related, it should be no surprise that the World Bank (1997) estimates 1.3 billion people are living in poverty (defined as US $\$ 1.00 /$ day or less). The precision of these numbers is important, but, for this article, the important issues are ethical. The numbers keep changing, but the ethical problems are constant.

The ethical question of resource distribution and allocation within the human species is of paramount importance. Before a systematic and orderly analysis of this issue of resource limits and allocation can be made, there are three important questions for which some numbers must be produced and some ethical issues addressed. First, how much of Earth's resources $(10 \%, 25 \%, 50 \%, 75 \%)$ must be allocated to other species (i.e. natural systems) so that sufficient natural capital and ecosystem services remain for maintaining human society? Second, how can the size of humankind's ecological footprint be adjusted to a sustainable level? Third, since there will be considerable uncertainty about both numbers, what safety factor should be used as a precautionary measure? Vitousek et al. (1986) have estimated that human society is co-opting approximately $40 \%$ of the photosynthetic energy of Earth (i.e. that energy converted by plants from sunlight to forms such as carbohydrates that are more suitable for use by humans). The percentage of the photosynthetic energy for the 'machinery' of nature to maintain natural capital and deliver the ecosystem services necessary for sustainability is unknown. However, since the hunter/gatherer stage of human society probably used less than $1 \%$, we may now be approaching a critical ecological threshold or might even have passed it. Worse yet, we have not even the crudest estimate of how long deprivation of resources would result in disequilibrium of the interdependent web of life or what metrics to use in estimating longterm needs of natural systems. Obviously, numeracy is essential in selecting which numbers should be generated as well as analyzing the data. Earth is both finite and inhabited by other life forms. Humankind cannot treat natural systems as commodities rather than an essential life support system.

Many numbers can be used to estimate the health of the global economy and of most nations. Comparatively few numbers are available to estimate the health of the 'economies' of the $30+$ million other species with which humans share the planet. Persuasive evidence indicates that some of these species have economic systems of their own (e.g. Tullock 1994). Yet these species, collectively called natural systems or the interde- pendent web of life, provide services upon which the survival of humankind and its economic system depend (e.g. Daily 1997). The combined value of these services has been estimated to be in excess of US \$33 trillion per year (Costanza et al. 1997). The survival of both humankind and its unique economic system depend upon natural systems, yet human society is acting as if only the numbers related to economic systems are of primary importance. The two sets of numbers are related.

Brown (2001) notes that economists see the environment as a subset of the human economy, and environmentalists see the human economy as a subset of the environment. However, global policy and that of most nations is based on numbers focused on the human economy rather than the environment. Almost all trends in natural systems (e.g. loss of old growth forests, depletion of oceanic fisheries, and increased production of greenhouse gases) are toward crisis conditions. Brown (2001) further notes the existence of a stressed relationship between human economy and Earth's ecosystems which, at some point, could overwhelm the worldwide forces of progress and lead to human economic decline. Despite this catastrophic probable outcome, most economic data gathered are used for personal or corporate economic gain. Environmental data are most commonly gathered to demonstrate compliance with governmental regulations. In neither case is the integrity of natural systems the primary goal. It is unlikely that numbers gathered to protect natural systems will be generated until the health of natural systems and their component species becomes an ethical/moral responsibility of humankind.

Ignoring the stressful relationship between human society and natural systems has caused collapse of both, as evidenced in the decline or collapse of early civilizations (e.g. Tainter 1998). Causes include not only degradation of the environment but climate change, civil conflict, and foreign invaders. For example, the ancient Sumerian civilization almost certainly had an environment in which humans flourished. Now vegetation is sparse and virtually absent in many areas. One possibility is an environmental flaw in the hydrologic design of the irrigation system (Postel 1999). Mismanagement of water, plus soil erosion, appears to have caused a falling food supply in Sumeria. Another example of collapse is Easter Island (e.g. Diamond 1994) in the Pacific Ocean, where the island was small enough for each human to see the entire system. Carrying capacity was exceeded and followed by a steep decline in the number of people able to survive. Hard numbers were not needed to demonstrate the inhabitants were living unsustainably because the gross changes should have been evident to even unobservant people. What appears to have been lacking 
was an ethical responsibility for future generations and even those alive at the time. Since there was a social organization (and its leaders) capable of quarrying stone, sculpting huge statues, and transporting them a considerable distance from the stone quarry, it is astonishing that there is no evidence of an attempt to live sustainably. The decline appears to have been precipitous, and its worst feature was cannibalism. Surely Easter Island's isolation obviated any chance for help from outside. However, Earth cannot expect help from elsewhere in the universe either.

Diamond (1997) describes an even more interesting situation involving three islands with a modest commerce between them, but which was essential to optimal use of all three. This interdependence is a small-scale model of the present global marketplace. Again, observant people should have realized they were not living sustainably. Still, the system collapsed. The spatial and temporal scales are much larger for the entire planet, but the basic problem remains unchanged - how does one use numeracy and eco-ethics to achieve sustainability?

\section{THE LIMITS OF NUMERACY}

The 'ancient' societies presumably did not have as much quantitative information as is available today, but each generally had fewer people per unit of area. They were probably as intelligent and may have been better informed about the entire system upon which they depended than modern people. They probably had a sense of the quantitative changes in the system upon which they depended. Today, food, fiber, and other resources come from a much larger area with which most individuals have minimal contact.

Situations involving complex natural systems require damage control without full proof of the consequences of doing nothing. Some individuals resist action until it can be based on objective evidence obtained by the scientific method. However, no single scientific method will suffice. An array of methods are available from which selections can be made, based on the nature of the problem, the amount of evidence already available, the complexity and variability of the system being studied, the consequences of an error in judgment, and the degree to which the chosen course of action is congruent with other established practices. The scientific method was developed to avoid mistakes that might lead to erroneous conclusions. However, biases exist at both the individual and collective levels. Given these circumstances, surprises will always be possible, so both science and public policy must be adaptive. Any monitoring system designed to detect error must provide early warnings in time for corrective action to be taken.
The comparative analysis of alternative courses of action should use quantitative data whenever it is available in a suitable form. The selection of the most suitable alternative should include the criteria used for the analysis and the realistic options that survived the process. It is also very important to state how the selected alternative will be implemented. Special interests will attempt to skew the selection process and will use every available political pressure to ensure an outcome that favors them. Furthermore, in the US (and presumably other countries as well), neither governmental nor non-governmental agencies/organizations have sufficient flexibility to cope with the complex problems of either sustainable use of the planet or the precautionary principle. To achieve this will require a much higher level of environmental literacy and a heightened sense of eco-ethics.

\section{NUMERACY AND PREVENTATIVE ACTION}

Sustainable use of the planet will require action to prevent significant damage to both natural capital and ecosystem services. In short, with the planet's huge human population, which is still growing, and equally rapid depletion of natural resources, mistakes and ecological 'surprises' could cost millions, even billions, of lives. Preventative action to avoid damage to natural capital and ecosystem services is essential. Not only should further damage be prevented, but lost natural capital should be restored. Fortunately, methods and procedures for monitoring the restoration of natural capital are available (e.g. Cairns 2002a). The same monitoring techniques can be equally useful in providing an early warning of threats to natural capital so that preventative action can be taken before serious degradation occurs. Estimating the health and integrity of dynamic, complex, multivariate systems is a formidable task with fairly high levels of uncertainty. But, the important aspect, in terms of this article, is that the level of statistical literacy required for even determining the appropriate metric for each situation is rather high. The difficulties of explaining the process of analyzing and interpreting the data to legislators, policymakers, and the general public boggle the mind. An illustrative list of potentially useful analyses follows. 1. Uncertainty analysis-focuses on the effects of uncertainty of all components thought to be a factor affecting the outcome of an analysis as well as the outcome itself.

2. Uncertainty matrix - a matrix intended to identify the location, category, and level of uncertainty for the purpose of estimating the total uncertainty associated with the outcome of the analysis.

3. Power analysis - estimates the risk of being wrong and for determining the effects of false positives and false negatives. 
4. 'Right' question analysis - have the right questions been asked in determining the components or issues to be analyzed?

5. Sensitivity analysis - estimates the effect a particular component has on the outcome of an analysis.

These are just a few examples of not only elements of a management plan to protect natural capital, but also the difficulty of assembling the analysis of each component so that the cumulative impact can be estimated.

\section{NUMERACY AND ECOLOGICAL DEFICITS}

An ecological deficit results when a significant deviation occurs from the nominative state or from a selfregulating ecological condition. Ecological deficits also have closely linked economic deficits. For example, deforestation and loss of old growth forests produce a variety of effects from shortage of fuel wood, increased erosion, major changes in the hydrologic cycle and the like. Excessive irrigation results in salinization of agricultural soils and consequent loss of productivity. Poor management practices result in expansion of deserts and deleterious effects of dust storms. Since a huge number of linkages exist in the complex system often referred to as the interdependent web of life, at some point these deficits act synergistically (combined effects greater than additive) and produce an ecological disaster of major proportions.

Ecological deficits must be calculated in ecological terms. Trying to frame deficits in monetary terms will not suffice. In one sense, ecosystems have infinite value since they constitute the planetary life support system without which humankind and its economic system could not survive. However, the size and extent of the deficit can be calculated. For example, the National Research Council (1992) has estimated the number of aquatic ecosystems (rivers, lakes, wetlands) that need restoration. The time and resources needed to accomplish this restoration can be calculated with reasonable precision. Since the rate of ecological damage greatly exceeds the rate of ecological repair, the deficit is increasing at a frightening rate. At some point, so many species will have been lost that restoration to predisturbance condition will no longer be possible. The task is already formidable and may already be beyond humankind's capacity to repair. The real danger to humankind is disequilibrium in the ecological life support system if conditions become intolerable. Even if restoration to predisturbance ecological condition is not possible, a naturalistic community of plants and animals might well be assembled that would provide comparable natural capital and ecosystem services that would favor humankind.

\section{ECOLOGICAL DEFICITS AND POLITICAL INSTABILITY}

Ecological deficits could cause major disruption to both national and global political systems. A variety of ecological disequilibrium conditions could produce millions of environmental refugees (e.g. Cairns 2002b). Numbers on the health of national and global economics are available daily, even hourly; however, no comparable numbers are available on ecological health, although the two are interrelated.

Brown (2002a) lists the categories of ecological deficits in China, whose 1.3 billion people and geographic size make the country a major factor in global ecological, economic, and political arenas. In China, eroding croplands, disappearing forests, deteriorating rangelands, and failing underground aquifers are interacting to produce a dust bowl of historic dimensions. All nations have ecological deficits, but China's is of crucial importance because of its population size and strategic location. On April 12, 2002, South Korea was engulfed by a huge dust storm originating in China, which had a variety of detrimental effects ranging from human health to disrupted airline schedules (French 2002). Dust storms in China can even affect the US (Brown 2002b). A dust and sand storm that occurred on May 5, 1993, in the Hexi corridor of Gansu Province in China's northwest reduced visibility to zero. The storm destroyed 170,000 hectares of standing crops, damaged 40,000 trees, killed 6,700 cattle and sheep, blew away 27,000 hectares of plastic greenhouses, injured 278 people, and killed 49. Fortytwo trains were canceled, delayed, or parked until the storm passed and the tracks were cleared of sand. The important lesson from this example is that an ecological deficit can cause additional deficits, sometimes very quickly. Even the modest data now available clearly demonstrate the need for corrective action.

\section{THE ROLE OF ECO-ETHICS AND SUSTAINABILITY ETHICS}

The global ecological deficit is enormous and rapidly growing. The problem is so spatially large and covers such a large range of time that securing adequate numbers in time will be virtually impossible. Preventing the deficit from increasing and gradually reducing the existing deficit are wise precautions that might well prevent a global catastrophe. Full use should be made of the numbers available, but the primary motivation must be ethics. A quote from Former US President Teddy Roosevelt fits the current situation beautifully: 'Far better to dare mighty things, to win glorious triumphs, even though checkered by failure, than to 
take rank with those poor spirits who neither enjoy much nor suffer much, because they live in the grey twilight that knows not victory nor defeat' (from Bartletts Familiar Quotations).

Leaders will be needed in every country and every region, and some nations will also have to become leaders. Ideally, the emerging leaders would primarily be from areas with the most abundant resources/capita since it is difficult for starving people to plan and think beyond their daily needs. And, if precautionary action is not taken soon, the majority of humankind will be starving. The US Department of Agriculture (2002) reported that the grain harvest in 2001 fell 40 million tons short of estimated consumption. ${ }^{1}$ The US is the world's leading wheat exporter. As Brown (2002b) notes, grain exports are, in reality, water exports, so food and water supplies are closely linked. The United Nations (2001) has already called attention to the need to restore the balance between water supply and human needs, which may depend on stabilizing population in water-deficit countries. Attempts to maintain the status quo on population increase and ever larger ecological footprints will eventually cause an ecological catastrophe so horrendous that even a fool will see it. This catastrophe can be avoided by shifting from exploitation of natural resources to sustainable use. Surprisingly, a major step in this regard can be taken at little cost to most of humankind.

\section{ELIMINATING PERVERSE SUBSIDIES}

Myers \& Kent (1998) define perverse subsidies as subsides that exert adverse effects upon economies and environments alike. Total subsidies (both perverse and beneficial) are estimated to be roughly US $\$ 2$ trillion worldwide per year (e.g. Panayotou 1993; United Nations Commission on Sustainable Development 1994). Many subsides, such as fostering overloading of croplands (e.g. erosion of topsoil), fossil fuel (e.g. air pollution, including greenhouse gases), road transportation (e.g. overuse of cars), water supply (e.g. overuse of water), fisheries (e.g. overharvesting), and forestry (e.g. excessive logging), are clearly perverse. Although this subject has been discussed (e.g. de Moor 1997; Roodman 1998), there is no general awareness of the extent to which subsidies damage the environment. From an eco-ethical standpoint, more numbers will not help answer the basic question - is it ethical to create more ecological deficits for future generations to reduce? From an eco-centric viewpoint - is it ethical

${ }^{1}$ See also US Department of Agriculture (2002) Production, supply, and distribution. Electronic database, updated 10 May 2002 (as quoted in Brown 2002b) to use other species as commodities, especially when they collectively constitute humankind's ecological life support system? In this case, the numbers are unambiguous-governments worldwide are subsidizing activities that harm the environment and often the economy as well. The US has numerous special interest groups that penetrate the political process. In the US capitol city, tens of thousands of lobbyists (as well as lawyers to keep them informed about various laws, loopholes, or about drafting new laws) attempt to affect laws. Between 1993 and mid-1996, American oil and gas companies gave US \$10.3 million to political campaigns and received tax breaks worth US $\$ 4.0$ billion. Meyer et al. (1992) report that depletion of soils, forests, and fisheries resulted in a 25-30 \% reduction in potential economic growth. Thus, at best, subsidies may help produce a short-term economic gain but a long-term loss. This strategy is not the way to achieve sustainable use of the planet.

\section{KNOWLEDGE AND COMPLICITY}

In July 2002, a jury of citizens in the State of Florida, US, found two Salvadoran generals responsible for torture of leftist insurgents. The charge against the officers was not that they tortured with their own hands but that they knew about human rights abuses perpetuated by men they commanded and did nothing to stop them. The sine qua non of international law and human rights abuses is that they must be universally applied - not just applied when they coincide with policy goals. If this is true for human rights abuses, should it not also be true for environmental abuses? Complicity is a partnership or involvement in wrongdoing and is most commonly interpreted as harm to humans. However, degrading the planet's ecological life support system also harms humans, although a modest level of ecological literacy is required to make this connection. Recently, I read an excellent ecology book intended for students in the fifth grade of school (approximately age 11). Surely it is not unreasonable to expect our leaders and the general public to have a grasp of ecology expected of students in the fifth grade. Either they are ecologically illiterate or they have the knowledge to be aware of wrongdoing. If the latter is true, they are guilty of complicity; if the former is true, they are not sufficiently literate to be either leaders or voters.

In a democratic state, it is the electorate that is ultimately responsible for this regrettable situation. Responsible citizenship requires focused attention. Alertness is essential, even if some of the details are boring. Affluent modern society appears to have chosen entertainment and other activities that diminish focused at- 
tention on environmental problems. Neil Postman (1986), in his book Amusing Ourselves to Death, remarks that 19th century farmers in the US turned out for hours-long debates between Abraham Lincoln (who subsequently became US President) and his opponent Stephen Douglas. The villagers were hardworking people who put in long, hard hours at work, but it did not affect their sense of responsibility. In the US, irresponsible acts such as 'road rage' are increasing. At the same time, voter turnout, financial support for education, retirement security, corporate accountability, and air quality are declining. This irresponsibility is not an appropriate condition for the world's only superpower, which one hopes would make sound decisions, especially on sustainability. Of course, sustainable use of the planet requires widespread ecological literacy and an informed citizenry in all the world's nations.

The present human population size and distribution is dependent upon both Earth's ecological life support system, consisting of natural capital and the ecosystem services it provides, and a technological/economic life support system. The metrics of the latter system are well known. Far less well known to elected and regulatory officials, as well as other decision makers, are the metrics of the ecological life support system. This system (the biosphere) operates at the global level with an array of subsystems of decreasing complexity, ranging from bioregions to ecosystems to communities to individual species. The type of decision being made will determine the specific metrics that are appropriate (e.g. Cairns \& Smith 1989; Cairns et al. 1993). Moreover, for sound decision making at all levels of biological organization, the connections between the different levels must be made clear. ${ }^{2}$

Some illustrative metrics for ecosystem restoration are in National Research Council (1992), Hoffman et al. (2003), and Holl \& Cairns (2003). Long-term effects, such as climate change, will require trend analysis. The metrics will provide an estimate of the condition of the ecological life support system, but the ultimate decision will be based on value judgments and ethics. Both the metrics and the ethics will require critical judgment and the reasoning behind each decision should be explicitly stated.

\section{ASSESSING \& COMMUNICATING NUMERACY}

In order to verify complicity, one needs to determine numeracy about sustainability. Some illustrative questions follow.

${ }^{2}$ Cairns J Jr (2003) Integrating top-down/bottom-up sustainability strategies: an ethical challenge. ESEP 2003:1-6. Available at http://www.esep.de/articles/esep/2003/E26.pdf

\section{Assessing numeracy}

1. What do leaders and the general public know about sustainability?

2. What level of numeracy do they have about sustainability?

3. What do government leaders and the general public think about these numbers?

4. What information (numbers) about sustainability do leaders and the general public understand?

5. What numbers still cause confusion?

\section{Communicating numeracy}

1. How can professionals communicate the issues of sustainability to leaders and the general public?

2. How can numbers that are important to the debate about sustainability be objectively introduced?

3. What can each person do to increase numeracy about sustainability so that effective implementation of the steps necessary to achieve this goal occurs?

\section{OBFUSCATION}

Special interest groups and the politicians indebted to them will often find ways to confuse the general public about the validity of even the most robust data. The attempt to obscure the primary issue is usually successful when the general public's literacy about sustainability is inadequate. Illustrative common tactics follow.

1. Assert that the numbers are inadequate. By asserting that the numbers were not derived by 'sound science,' the need to take action on important measures to achieve sustainable use of the planet is delayed or entirely blocked. Typically, no effort is made to describe why the numbers are inadequate. Why make the attempt when the accusation alone accomplishes the objective?

2. Assert that more data are needed. All science is probabilistic, so some uncertainty will always exist. Those asserting that more data are needed should at least describe the type of data needed and at what level of uncertainty a decision will be justified. If the outcome is likely to have severe or catastrophic consequences (e.g. global warming), precautionary measures are justified even when uncertainty is high.

3. Urge that another committee be organized to 'study' the problem. This tactic is very successful because, if committee members are selected who have trouble making a decision, the report will take a considerable amount of time and might well confuse the issue further rather than clarifying it. 
4. Use of irresponsible 'expert' witnesses. All scientists should give every hypothesis a rigorous testing. Regrettably, some individuals will, for a substantial consulting fee, vigorously support the cause of a special interest group. All too often, such individuals are poorly qualified but get attention in courts of law, the news media, etc., so that all 'points of view' will be heard. Mainstream science may be totally against this view, but the contrary view of one individual will get a disproportionate amount of time. Mainstream science is occasionally wrong, but far fewer times than expert witnesses advocating the position of a special interest group.

5. Inappropriate use of courts of law to make decisions on scientific evidence. Courts of law are essential to any civilized society, but they are not equipped to evaluate scientific evidence. However, there are no comparable 'courts of science.' Courts of law have not functioned well on such varied issues as global warming, population control, preservation of biodiversity, restoration of damaged ecosystems, protection of ground water aquifers, preservation of wild areas, and a variety of related issues. Either the general public will have to acquire a higher level of numeracy or a court they trust will have to be established to make judgments requiring numeracy. Since elected leaders are unduly influenced by special interest groups making huge contributions to campaign funds, it is unlikely that numbers will routinely be used in an eco-ethical way. This dilemma can only be resolved by an informed electorate with a commitment to eco- and sustainability ethics. Leaders of non-democratic countries may be influenced by world opinion and the expectation that economic well-being requires sustainability.

\section{CONCLUSIONS}

Sustainability (sustainable use of the planet) requires a combination of numeracy and eco- and sustainability ethics. With increasing pressure on finite resources and humankind's dependence upon the planet's ecological life support system, both numeracy and eco- and sustainability ethics are essential to achieve sustainable use of the planet. A major ecological catastrophe that could have been avoided would probably suffice, but one hopes that intelligence guided by reason and eco- and sustainability ethics might help avoid major catastrophes, or at least reduce both their numbers and magnitude.

Acknowledgements. I am indebted to H Cairns for transferring the handwritten first draft to the word processor and to $\mathrm{K}$ Cairns for doing so for the second draft. D Donald provided her usual skilled editorial assistance.

\section{LITERATURE CITED}

Bartlett AA (1994) Arithmetic, population, and energy. VHS videotape. Information Technology Services, University of Colorado, Boulder, CO, US

Bartlett, AA (1998) Malthus marginalized: the massive movement to marginalize the man's message. The Social Contract VII(3):239-251

Brown LR (2001) Eco-economy: building an economy for the earth. WW Norton, New York

Brown LR (2002a) The economic costs of ecological deficits. In: Brown LR (ed) The earth policy reader. WW Norton, New York, p 5-29

Brown LR (2002b) Deserts invading China. In: Brown LR (ed) The earth policy reader. WW Norton, New York, p 7-28

Cairns J Jr (2002a) Monitoring the restoration of natural capital: water and land ecosystems. In: Younas $\mathrm{T}$ (ed), Advances in water monitoring research. Water Resources Publications, LLC, Highlands Ranch, CO, p 1-31

Cairns J Jr (2002b) Environmental refugees. The Social Contract XIII(1):34-44

Cairns J Jr, McCormick PV, Niederlehner BR (1993) A proposed framework for developing indicators of ecosystem health. Hydrobiologica 263(1):1-44

Cairns J Jr , Smith EP (1989) Developing a statistical support system for environmental hazard evaluation. Hydrobiologia 184:143-151

Costanza R, d'Arge R, de Groot R, Farber S and 9 others (1997) The value of the world's ecosystem services and natural capital. Nature 387:253-260

Daily G (ed) (1997) Nature's services: societal dependence on nature's services. Island Press, Washington, DC

de Moor APG (1997) Perverse incentives: hundreds of billions of dollars now harm the economy, the environment, equity and trade. Earth Council, San Jose, Costa Rica

Diamond J (1994) Ecological collapses of ancient civilizations: the golden age that never was. Bull Am Acad Arts Sci XVLII(5):37-59

Diamond J (1997) Paradises lost. Discover 18:68-78

French HW (2002) China's growing deserts are suffocating Korea. New York Times, 14 April, natl. ed.: p 3

Hardin G (1993) Living within limits. Oxford University Press, New York

Hoffman DJ, Rattner BA, Burton GA Jr, Cairns J Jr (eds) (2003) Handbook of ecotoxicology, 2nd edn. Lewis Publishers, CRC Press, Boca Raton, FL

Holl KD, Cairns J Jr (2003) Landscape indicators in ecotoxicology. In: Hoffman D, Rattner BA, Burton GA Jr, Cairns J Jr (eds), Handbook of ecotoxicology, 2nd edn. Lewis Publishers, CRC Press, Boca Raton, FL, p 411-432

Malthus TR (1798) An essay on the principle of population. In: Appleman P (ed) (1976) Norton critical edition. WW Norton, New York

Meyer CA, Cruz MC, Repetto R, Woodward R (1992) Population growth, poverty, and environmental stress: frontier migration in the Philippines and Costa Rica. World Resources Institute, Washington, DC

Myers N, Kent J (1998) Perverse subsidies: tax \$s undercutting our economies and environments alike. International Institute for Sustainable Development, Winnipeg, Manitoba, Canada

National Institute for Public Health and Environmental Protection (1992) National environmental outlook 2, 1990-2010. Bilthoven, Netherlands

National Research Council (1992) The restoration of aquatic ecosystems: science, technology, and public choice. National Academy Press, Washington, DC 
Panayoton T (1993) Green markets. Institute for Contemporary Studies Press, San Francisco

Postman N (1986) Amusing ourselves to death. Penguin Press, New York

Postel S (1999) Pillars of sand. WW Norton, London

Roodman DM (1998) The natural wealth of nations: harnessing the market for the environment. WW Norton, New York

Tainter J (1998) The collapse of complex civilizations. Cambridge University Press, Cambridge

Tullock G (1994) The economics of non-human societies. Pallas Press, Tucson, AZ

United Nations (2001) World population prospects: the 2000 revision. United Nations Press, New York

United Nations Administrative Committee on Coordination and the International Food Policy Research Institute (2000)

United Nations Commission on Environment and Development

Editorial responsibility: David R. Orvos, PhD (Editor)

Sweet Briar, VA, USA
(1987) Our common future. Oxford University Press, Oxford United Nations Commission on Sustainable Development (1994) Financial resources and mechanisms for sustainable development: overview of current issues and development. United Nations Press, New York

US Department of Agriculture (2002) World agricultural supply and demand estimate. Washington, DC

Vitousek P, Ehrlich PR, Ehrlich AH, Matson P (1986) Human appropriation of the products of photosynthesis. BioScience 36:368-373

Wackernagel M, Rees W (1996) Our ecological footprint. New Society Publishers, Gabriola Island, British Columbia, Canada

World Bank (1997) Rural development: from vision to action. Environmentally and Socially Sustainable Development Studies and Monographs Series No. 12. World Bank, Washington, DC

Submitted: August 28, 2003; Accepted: November 7, 2003 Proofs received from author(s): November 14, 2003

Published on the web: November 20, 2003 